\title{
Sensorial Impact of Sotolon as the "Perceived Age" of Aged Port Wine
}

\author{
A C. Silva Ferreira ${ }^{*^{*}}$, I.M.L.B. Ávila ${ }^{\S}$ and P. Guedes de Pinho* \\ \$- Escola Superior de Biotecnologia, Universidade Catolica Portuguesa, Rua \\ Dr. Antonio Bernardino de Almeida, PT-4700-072 Porto, Portugal \\ ; ${ }^{\S}$ Departamento Química - Universidade de Aveiro - Portugal. \\ ${ }^{(*)}$ Corresponding author : Tel : +351 225580095 ; Fax : +351225580088 ; E- \\ mail : Ferreira@esb.ucp.pt,
}

During the barrel ageing of Port wine, a number of specific compounds accumulate progressively. One such compound is Sotolon, which imparts a typical aroma which thus increases in intensity with age. To correlate Sotolon levels with sensorial determined "age perception", a simple ranking test was applied to 3 sets of wines: a $4 \mathrm{y}$. o., a 10 years old and a 40:60 blend of these. Increasing quantities of Sotolon were added and wines supplemented with this substance were consistently ranked as older. The Sotolon formation was studied as a function of, temperature, $\mathrm{pH}, \mathrm{SO}_{2}$ and dissolved $\mathrm{O}_{2}$. The synergic effect of temperature and high regimes of $\mathrm{O}_{2}$ had the highest impact on furanone concentration. A 1st order kinetic model was applied to describe both saturated and nonsupplemented regimes of $\mathrm{O}_{2}$ on Sotolon formation. Arrhenius equation described well the temperature dependence of the reaction rate constants. The presence of Sotolon is greatly dependent on $\mathrm{O}_{2}$ regimes during aging, have a major impact

\section{RESERVE THIS SPACE}


on "age perception" in barrel storage Port wines.

\section{Introduction}

Port is a naturally sweet wine produced by interrupting alcoholic fermentation by the addition of grape spirit. These red wines, with an alcohol level of about $20 \%$ vol. and a few tens $\mathrm{g} / \mathrm{L}$ of residual sugar suffers long periods of ageing ( $>4$ years), either for bottle aged ("Vintage" category) or barrel aged ("Tawny" and "Colheita" categories) wines, up to 60 years and more. During this maturation period wine suffers a number of compositional changes, the level of some substances decreasing over time whilst others increase or arise in wine. Changes are become more pronounced with extended aging, having significant effects on the color and aroma of the wine.

The typical aroma developed during barrel storage, is the consequence of this chemical behavior, and is usually described as "maderised", "rancio" "burnt", "dry fruit", "nutty" and "spicy". The value of the product is related with the characteristic aroma developed during this long maturation. Aroma perception, is one of the most important parameters in food evaluation, the quality of barrel aged port wine, is evaluated basically on these sensorial properties. Moreover the age certification of this product is also based on the sensorial analyses effectuated by the "Instituto do Vinho do Porto" (IVP).

It has been suggested that the presence of aldehydes and methyl-ketones, like in white wines (1), were related to the "rancio" odor of barrel aged Port wine (2). Others volatiles, were also studied on ports $(3,4,5,6,7,8)$. More recently, 3-hydroxy-4,5-dimethyl-2(5H)-furanone (Sotolon) has been suggested to be a key odorant in the aroma of aged port (9). This highly odor active molecule has shown to contribute to the aroma of Jura wines "vin jaunes" (10, 13, 14, 15), "vins doux naturels" (14) Tokay wines (11), Botrytised wines (16) and Sherry wines (12).

The presence Sotolon in foodstuff has been first explained as the result of aldol condensation between 2-ketobutyric acid and pyruvic acid (10), similar to the mechanism proposed for the 5-ethyl-3-hydroxy-4-methyl-2(5H)-furanone (abexon) formation in protein hydrolisates (17). The aldol condensation between acetaldehyde and 2-ketobutyric acid has also been suggested (11) to explain the presence of Sotolon in fortified type wines.

Other mechanisms, which excluded the inclusion of 2-ketobutyric acid as a reactant has also been reported. That is the case of Sotolon formation from the chemical or enzymatic conversion of 4-hydroxisoleucine $(18,19)$; as a product of reaction from hexoses and pentoses in the presence of cysteine (20); from the aldol condensation of hydroxyacetaldehyde and buta-2,3-dione (21) and more 
recently (22) it has been demonstrated that Sotolon can be formed from ascorbic acid degradation products.

It is important to determine in which extent some of the common industrial practices like, $\mathrm{SO}_{2}$ additions, $\mathrm{pH}$ corrections, or type and volume of wine containers, related with levels of dissolved oxygen, affects the rate of key odorants formation. Once isolated the critical parameter the mathematical modelisation can be attempted in order to quantify the impact on flavour formation. Kinetic studies are very important to know the extent of a specific chemical reaction, the rate at which the changes occur and also to be able to optimize the food processing or storage conditions. The knowledge and control of kinetics parameters can greatly enhance the rate of generation of the desired flavour compounds $(23$.

Hence the aim of this work was to : (i) evaluate the impact of Sotolon on the "perceived age" of Port wine ; (ii) determining among some technological parameters such as, temperature, dissolved oxygen, $\mathrm{pH}$ and free $\mathrm{SO}_{2}$ content, those having the greatest effect on furanone concentration, (iii) and to establish mathematical models describing the rate of formation of Sotolon during time of storage, taking into account the critical technological parameters selected.

\section{Material and Methods}

\section{Wine material: - Port Wine Samples.}

Samples from "Colheita" category were aged in "pipas" (550 L spent-oak barrels) and those from "Vintage" category were aged in bottle until analysis. They were supplied by the Instituto do Vinho do Porto (IVP) after certification.

Wine Group 1 - Thirty-five samples of a single harvest ranging from 1 to 60 year-old "Colheitas" and seven samples of a single harvest ranging from 3 to 16 yers-old "Vintage" categories.

Wine Group 2 - "Forced Ageing" experimental protocol: This protocol is similar that of a previous study (8). Red port wine 2 years-old (8L), with a $\mathrm{pH}=3.7$, an amount of dissolved oxygen of $4.2 \mathrm{mg} / \mathrm{L}$, with a instantaneous potential of $222 \mathrm{mV}$ and a free $\mathrm{SO} 2$ level of $17 \mathrm{mg} / \mathrm{L}$, was prepared in order to analyze the effect of parameters which are believed to be important in the aromatic modification of port wines, namely temperature, oxygen concentration, $\mathrm{pH}$ and $\mathrm{SO}_{2}$ concentration (figure 1). 


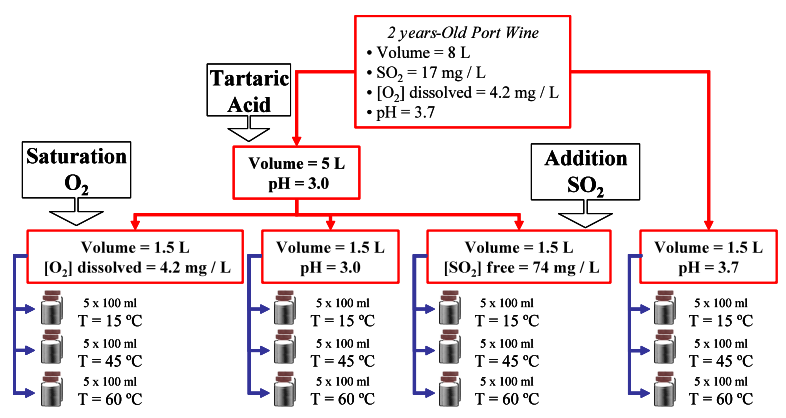

Figure 1. Schematic representation of the preparation of the "forced aging"

protocol.

To test the effect of $\mathrm{pH}$, one of the portions was adjusted to $\mathrm{pH} 3$ by adding tartaric acid. To test the effect of high concentrations of oxygen (oxidative environment) and the effect of an exogenous antioxidant, a portion of wine at pH3.0 was, saturated with oxygen $(6.2 \mathrm{mg} / \mathrm{L})$ by air bubbling, and finally to the last portion of wine at $\mathrm{pH} 3$, free $\mathrm{SO} 2$ was adjusted to $74 \mathrm{mg} / \mathrm{L}$ by adding potassium metabisulphite. The initial wine, having a $\mathrm{pH}=3.7$, was named $\mathrm{pH} 3.7$ in the text. As shown in figure 1, the 4 portions, each 1.5 litres, were divided into sets five of $100 \mathrm{~mL}$ and they were stored in sealed glass vessels. One part of each experiment was kept at $15^{\circ} \mathrm{C}$, another one at $45^{\circ} \mathrm{C}$ and the last one at $60^{\circ} \mathrm{C}$. The samples were analyzed at $0,17,32,47$ and 59 days of storage time. The samples initially saturated with oxygen were re-saturated $(7-8 \mathrm{mg} / \mathrm{L})$ at each sampling stage. This experiment was performed in duplicate.

Wine Group 3 - Kinetics Studies: 3 liters of 2 year-old Port wine $\mathrm{pH}=3.6$, an amount of dissolved oxygen of $1.2 \mathrm{mg} / \mathrm{L}$, with a instantaneous potential of $252 \mathrm{mV}$ and a free SO2 level of $22 \mathrm{mg} / \mathrm{L}$, was divided in 2 portions; one was saturated with oxygen, and the other was kept in absence of oxygen. Each portion was further divided and stored in sealed vessels at a temperature after $20,30,40,50$ and $60{ }^{\circ} \mathrm{C}$ during 77 days. Samples were analyzed at 0, 22, 30, 37 and 77 days. The samples initially saturated with oxygen were re-saturated (7-8 $\mathrm{mg} / \mathrm{L}$ ) at each sampling time.

\section{Sensorial studies}

Sensorial panel: The sensory panel employed in all sensorial measurements in this work was composed of eighteen persons; university students; Port winemakers and laboratory personnel. The panel is permanent and receives weekly training sessions. Tests were performed in individual booths, using tulip glasses containing $30 \mathrm{~mL}$ of wine at room controlled temperature of $20^{\circ} \mathrm{C}$. 
Ranking testing: The impact of the Sotolon in the typical aroma of aged Port wine was evaluated using Ranking tests carried out on wine samples of different ages with or without additions of Sotolon. Tests were performed in individual booths, red light was used to mask visual differences between samples. The results were collected after three tasting sessions with a trained sensorial panel of 18 assessors using the same sample preparation for each session.

Two wines, certified by IVP, of respectively of 4 year-old ("Ruby") and 10 year-old ("10 anos") were used. In order to obtain a "middle sample", these two wines were blended, a mixture of $40 \%$ "Ruby" with $60 \%$ "10Anos" was chosen ("Blended-sample"-BS).

Three sets were studied, samples were supplemented with three different levels of Sotolon $25 \mu \mathrm{g} / \mathrm{L} ; 50 \mu \mathrm{g} / \mathrm{L}$ and $100 \mu \mathrm{g} / \mathrm{L}$. Each set had five samples, one with no addition, three supplemented samples and one different wine sample common with the next set as described in figure 2 .

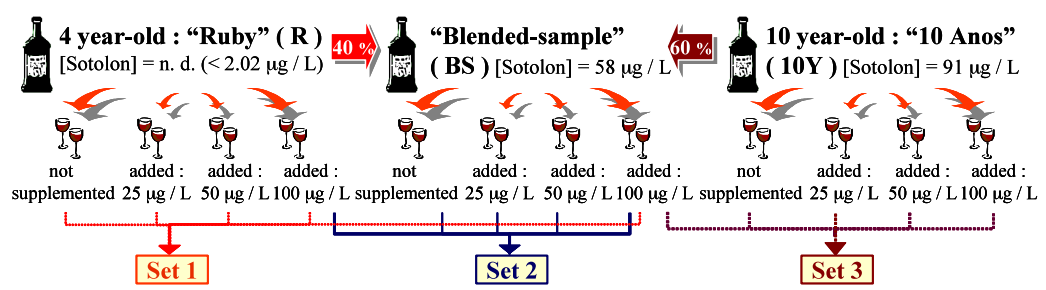

Figure 2 : Sensorial protocol: Wine samples preparation.

Samples were randomly codified using four alphanumeric characters. Each set was presented individually, on different days, to each assessor (three per session). The panelist were instructed to smell but not to taste and then order by age using a scale from 1 (youngest) to 5 (oldest) with unit intervals, rank repetition was not allowed. The correlation coefficients between the ranks for each assessor were calculated using Spearman test (24). The ranks were converted to scores according to the method of Fisher and Yates (25). The sample ranked first of five was given a value of -1.16 ; the second -0.5 ; the third 0 ; fourth +0.5 and the fifth +1.16 . The scores were then subjected to analysis of variance (ANOVA) in order to check if there was a significant difference among samples (at 5\% level). To determine which samples were significantly different from another, Tuckey's test was used. Samples were arranged according to magnitude, and the Honestly Significant Difference at 95\% (HSD) was determined. Any two samples that differed by a value equal to or more than the HSD were regarded as significantly different (26).

\section{Chemical Studies}


Chemicals were obtained from Sigma-Aldrich, (Saint Quentin Fallavier, France): 3-hydroxy-4,5-dimethyl-2(5H)-furanone (W36,340-5) (97\%) and 3octanol (21,840-5) (99\%).

Hydroxy-4,5-dimethyl-2(5H)-furanone quantification : Extraction procedure: To $50 \mathrm{~mL}$ of wine were added $50 \mu \mathrm{L}$ of 3-octanol in hydroalcoholic solution $(1 / 1, \mathrm{v} / \mathrm{v})$ at $466 \mathrm{mg} / \mathrm{L}$ as internal standard and $5 \mathrm{~g}$ of anhydrous sodium sulphate (increases extractability). The wine was extracted twice with $5 \mathrm{ml}$ of $\mathrm{CH} 2 \mathrm{Cl} 2$ (Merck, Spain). The two organic phases obtained were blended and dried over anhydrous sodium sulphate. Two $\mathrm{mL}$ of this organic phase was concentrated 5 times under a nitrogen stream with a $1 \mathrm{~mL} / \mathrm{min}$ gas flow. Extracts were analyzed using a Varian CP-3800 gas chromatograph (USA) equipped with a Varian Saturn 2000 mass selective detector (USA) and a Saturn GC/MS workstation software version 5.51. The column used was STABILWAX-DA (60 $\mathrm{m} \times 0.25 \mathrm{~mm}, 0.25 \mu \mathrm{m}$ ) fused silica (Restek, USA). The injector port was heated to $220{ }^{\circ} \mathrm{C}$. The split vent was opened after $30 \mathrm{sec}$. The carrier gas was Helium C-60 (Gasin, Portugal), at $1 \mathrm{ml} / \mathrm{min}$, constant flow. The oven temperature was $40{ }^{\circ} \mathrm{C}$ (for $1 \mathrm{~min}$ ), then increased at $2{ }^{\circ} \mathrm{C} / \mathrm{min}$ to $220^{\circ} \mathrm{C}$ and held for $30 \mathrm{~min}$. All mass spectra were acquired in the electron impact (EI) mode. The Ion Trap detector was set as follows: The transfer line, manifold and trap temperatures were respectively 230,45 and $170{ }^{\circ} \mathrm{C}$. The mass range was 33 to $350 \mathrm{~m} / \mathrm{z}$, with a scan rate of $6 \mathrm{scan} / \mathrm{sec}$. The emission current was $50 \mu \mathrm{A}$, and the electron multiplier was set in relative mode to autotune procedure. The maximum ionization time was $25000 \mu \mathrm{sec}$, with an ionization storage level of $35 \mathrm{~m} / \mathrm{z}$. The injection volume was $1 \mu \mathrm{L}$ and the analysis was performed in Full Scan mode. Detection and quantification thresholds were established in a Port wine diluted with $20 \%(\mathrm{v} / \mathrm{v})$ aqueous-alcoholic solution and were found to be respectively 1.17 and $2.02 \mu \mathrm{g} / \mathrm{L}(9)$.

Other analytical measurements: Measurements Redox potential, free $\mathrm{SO}_{2}$ concentration and chromatic index were performed (27). Acetaldehyde, higher alcohols (28), acetals (7), 2-Ketobutyric acid (9) and furanic aldehydes (29) were determined. The concentration of dissolved oxygen was measured using a "WTW 340 Oxygen Probe".

Kinetic analysis: Statistical data analysis was performed using the Statistica program version $6.0(30)$. The most usual kinetic models reported in literature to describe kinetic of compound formation are zero order $[\mathrm{c}=\mathrm{c} 0+\mathrm{kt}]$, first order $[\mathrm{c}=\mathrm{c} 0 \exp (\mathrm{kt})]$ or second order $[1 / \mathrm{c}=1 / \mathrm{c} 0+\mathrm{kt}]$ reaction models. The Arrhenius equation $\mathrm{k}=\mathrm{kref} \exp (-\mathrm{Ea} / \mathrm{R} *(1 / \mathrm{T}-1 / \mathrm{Tref}))]$ is usually applied to evaluate the effect of temperature on the reaction rate constant (31). For both regimes of oxygen concentration a one step nonlinear regression method was performed and a regression analysis of the residuals was also carried out (32).

\section{Results and Discussion}




\section{Sensorial Studies}

The estimation of the importance of Sotolon in the typiccity and persistence of aroma for "flor sherry" has already been established (12). Nevertheless, in order to gather more information concerning the impact of Sotolon on the typical aroma associated by the consumer with the age of Port wine, sensorial analyses needed to be carried out.

Ranking results: A trained panel was given, three sets of wines supplemented with three levels of lactone as described in the material and methods section. The panel asked to rank the sample from youngest (1) to the oldest (5) based only on the perceived aroma.

The correlation between the rank order for age attributed by each assessor and the rank order for Sotolon concentration in samples (or real age) was calculated by the Spearman method (24). The ranks were converted into scores, and the ANOVA treatments, for 95\% significant level, showed for each set no differences between assessors and differences among samples with a p-value for Sets 1 (4 years old), 2 (blended-sample) and 3 (10 years old) of p-value $=1.233 \mathrm{E}$ $17 ; \mathrm{p}$-value $=1.489 \mathrm{E}-17$ and $\mathrm{p}=1.252 \mathrm{E}-11$ respectively. Results are shown in figure 3 .

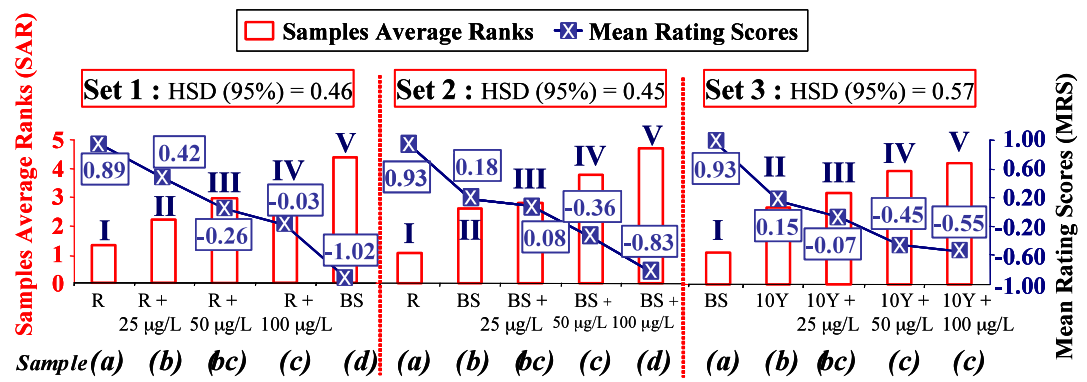

$\left|\mathrm{MSR}_{\mathrm{i}}-\mathrm{MSR}_{\mathrm{j}}\right| \geq \mathrm{HSD}$

(*) Samples not followed by the same letter are significantly different at $5 \%$ level.

Figure 3 : Samples evaluation results of the multiple comparison test (Significant level $=95 \%$ ).

To determine which samples differ significantly in "average ranked-age" after scoring translation, the comparison of the samples mean scores using HSD was calculated. Samples for the 3 sets were ranked by the panel on an increasing manner according to the real age and the increasing levels of Sotolon additions (Samples Average Rank). For Set_1 and Set_2 samples I, II, and V are significantly different from each other. The lower level of Sotolon addition on 
Set_1, was considered different from the sample not supplemented (I / II). This was not verified on Set_2 (II / III), due to the Sotolon concentrations present being close to the odor threshold $19 \mathrm{mg} / \mathrm{L}$ (1). In the second set it is important to note Sample V clearly rated as the oldest. Within Set_ 3 the differences are not so marked, nevertheless samples supplemented with $50 \mathrm{mg} / \mathrm{L}$ and $100 \mathrm{mg} / \mathrm{L}$ differed from the non-supplemented samples. These findings have already been reported in (9).

\section{Chemical Studies}

Sotolon Levels in Wines. The concentrations of 3-hydroxy-4,5-dimethyl$2(5 H)$-furanone increases with the storage time in barrel from a few tens $\mu \mathrm{g} / \mathrm{L}$ in young wines, to about $100 \mu \mathrm{g} / \mathrm{L}$ in 10 year-old wines and reaching $200 \mu \mathrm{g} / \mathrm{L}$ after 10 additional oxidative aging years. The highest contents were observed for wines older than 50 years, i.e. almost $1 \mathrm{mg} / \mathrm{L}$ (figure 4). The same kind of behavior was also observed for bottle-aged wines the "Vintage" type (figure 4). Both categories, presented a high correlation coefficient calculated $(r>0.90)$ clearly demonstrated the dependence of Sotolon contents on the storage time.

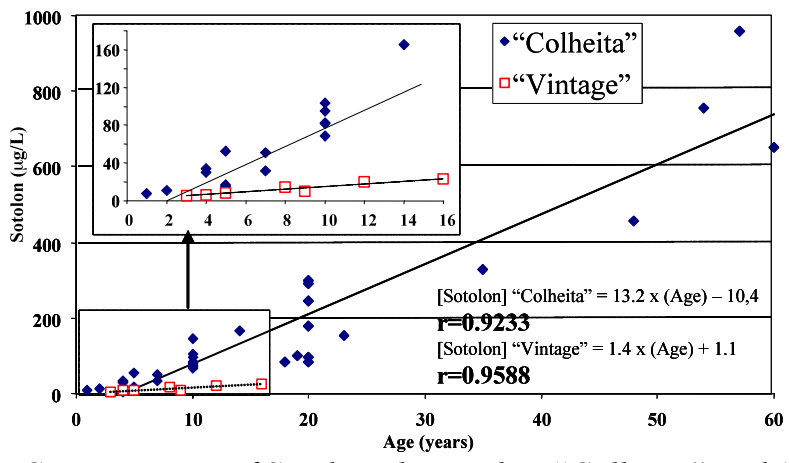

Figure 4: Concentration of Sotolon observed in "Colheita" and "Vintage" categories Port wine $(\mu \mathrm{g} / \mathrm{L})$.

Nevertheless, and in spite of the fewer samples of "Vintage" wines analyzed, it appears clearly that considering the same period of aging (16 years), the rate of formation of Sotolon is substantially higher, close to 10 -fold higher in "Colheitas". Thus, the levels of dissolved oxygen, seems to play a determinant role on the kinetics of Sotolon formation. In fact, the typical values of dissolved oxygen measured in barrel on Port wines cellars were close to $2-4 \mathrm{mg} / \mathrm{L}$ whilst it has been extensively reported that this concentration is inferior to $0.5 \mathrm{mg} / \mathrm{L}$ in bottle. It is also important to note, that the descriptors associated with bottle- 
aged port wines are related with "floral" and "fruit-like" a "younger" aroma character, when compared with the typical notes of oxidative aging. Considering uniquely the single effect of Sotolon in Port wine expressed by the "Odor Aroma Value" [OAV = (odor threshold / concentration $)_{\text {matrix }}$ ] this substance has a positive impact on aroma of barrel storage wines close to 10 year-old (OAV > 1) while in bottle-aged Ports this is only observed after 20 years or more. These results are in close agreement with the empirical observation in the Port wine industry upon which the "rancio" aroma constitutes a "quality factor" for wines aged in barrels for more than 10 years old, while it is not considered a major attribute of the global aroma of "Vintage" categories.

Sotolon Formation: Among the mechanisms reported in literature concerning 3-hydroxy-4,5-dimethyl-2(5H)-furanone formation, two seem to be of particular interest in order to explain the formation of this molecule in Port wine. Both involve a common step the aldol condensation between two carbonyl compounds followed, by cyclization. In "vin jaune" Sotolon could be formed during ageing by the aldolic condensation between acetaldehyde and 2oxobutyric acid produced from threonine by an enzymatic reaction, only possible due to the presence of a yeast belonging to the Saccharomyces genus and commonly denominated "flor" (13). In Port wine, this "flor" is absent; therefore, there is no microbial intervention after the end of alcoholic fermentation, with the exception of some contamination due to an alcohol resistant lactic bacteria (33). However, a strictly chemical degradation of threonine into 2-Ketobutyric acid, has also been suggested under acidic conditions (34) (Figure 5).

Figure 5: Sotolon formation pathway (I) Saké (34) ; (II) wines vins jaunes (13).

The presence of 2-ketobutyric acid in Port wine was investigated (9). Although the quantities found could reach $2 \mathrm{mg} / \mathrm{L}$, these were always lower than $0.5 \mathrm{mg} / \mathrm{L}$ for wines older than 10 years. No correlation between the levels of keto-acid neither with age nor with the amount of furanone could be found. Conversely a very high correlation was observed with acetaldehyde $(\mathrm{r}=0.8906)$. Thus, 2-ketobutyric acid may contribute to Sotolon formation, but taking into account the linear trend observed with time for the furanone levels, it seems unlikely that this keto-acid constitutes the only source of Sotolon in Port wine.

In addition, other works showed that 3-hydroxy-4,5-dimethyl-2(5H)furanone can be formed thanks to Maillard reaction from some hexoses and pentoses in the presence of cysteine (20). Due to the non-linear structure of 
Sotolon, its formation cannot simply be explained directly from sugar cyclisation during the Maillard reaction, like other furanones such as furaneol. Hence, the authors suggest that Sotolon results from rearrangements of Amadori products of low molecular weights like the butane-2,3-dione (diacetyl) and hydroxyacetaldehyde, being Sotolon formed by an aldolic condensation between these two molecules (figure 6).

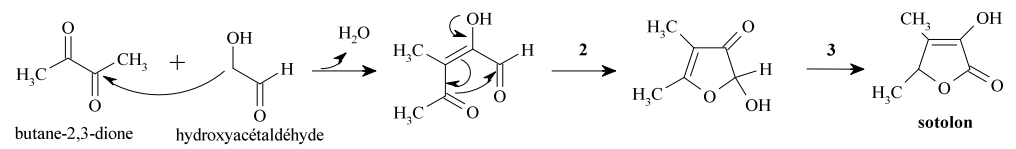

Figure 6 : Mechanisms of Sotolon formation by Maillard reaction (21).

Although the presence of hydroxyacetaldehyde needs to be confirmed, diacetyl levels in Ports can reach almost ten $\mathrm{mg} / \mathrm{L}$. Furthermore, taking into account the high levels of sugar present on Port wine (approximately $100 \mathrm{~g} / \mathrm{L}$ ) and the high correlation coefficient of furanic aldehydes sugar degradation products with Sotolon, like furfural, 5-methylfurfural and in particular 5hydroxymethylfurfural $(\mathrm{r}=0,9015)$, this last mechanism seems to fit the observed behaviour of the continuous formation of Sotolon during aging.

Forced Aging Experiment : On an empirical basis, Sotolon appearance seems to be closely related with oxygen regimes during storage. For this reason, an experimental protocol was established in order to evaluate the effect of some parameters which are believed to be important in the aromatic modification of port wines, namely temperature, oxygen concentration, $\mathrm{pH}$ and $\mathrm{SO}_{2}$ concentration.

As shown in figure 7 , the formation of Sotolon is clearly related to temperature and to the presence of oxygen in the wine

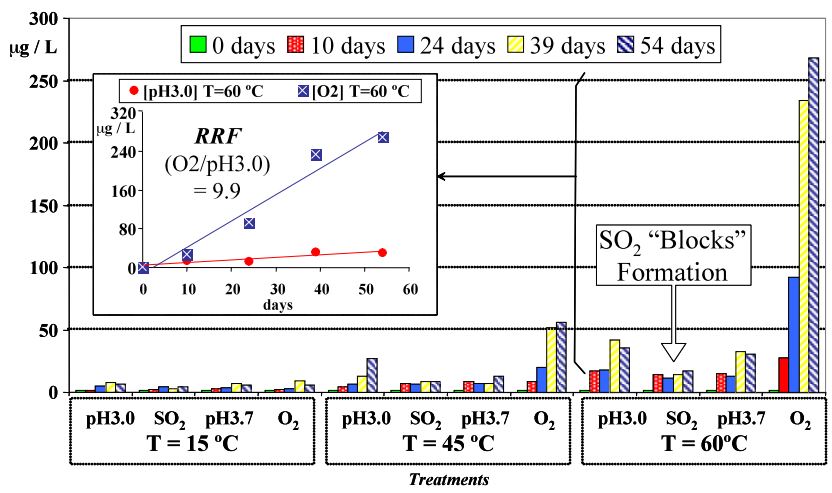


Figure 7 : 3-hydroxy-4,5-dimethyl-2(5H)-furanone, concentrations in samples of the "forced aging" experiment and the relative rate of formation $(R R F)$ for treatments $\mathrm{O} 2 / \mathrm{pH} 3.0$ at $\mathrm{T}=60{ }^{\circ} \mathrm{C}$.

In fact, none of the treatments at $15{ }^{\circ} \mathrm{C}$ led to significant changes in the concentration of this furanone. On the other hand, at $45{ }^{\circ} \mathrm{C}$ there was a considerable increase in its amount with time, except for the samples treated with $\mathrm{SO}_{2}$. The same behavior was observed for samples stored at $60{ }^{\circ} \mathrm{C}$, with particular emphasis for the samples treated with oxygen. In fact, the large amounts of Sotolon found in this set are noteworthy: After 59 days of storage at $60{ }^{\circ} \mathrm{C}$, the concentration of Sotolon reached $300 \mu \mathrm{g} / \mathrm{L}$, for a total of $22 \mathrm{mg} / \mathrm{L}$ consumed oxygen. The relative rate of formation $(R R F)$ of this substance was estimated in a rough manner by considering that the concentration changes linearly with time. The ratio of the respective slopes was calculated and the results have shown that the rate of formation observed for this substance is ten times higher for $\mathrm{O}_{2}$ treated samples than for $\mathrm{pH} 3.0$ (non-supplemented) samples.

Conversely, we found that $\mathrm{SO}_{2}$ treatment "blocks" furanone formation. These results are in agreement with those published previously (35). This observation can be explained by two reasons (i) the consumption of dissolved oxygen due to the high reactivity of this species with sulfur dioxide and (ii) the combination of $\mathrm{SO}_{2}$ with the carbonyl group of the precursors consequently blocking the aldol reaction.

The amounts in Sotolon are mainly dependent upon, by decreasing order of importance, the temperature and the amount of dissolved oxygen, and $\mathrm{SO}_{2}$ plays an important role as a "inhibitor" on furanone formation.

Kinetics Studies : After determining the technological parameter with the highest effect upon Sotolon concentrations in port wines, attempts were made to establish a mathematical model, which reflects the impact of oxygen regimes, temperature as well as the time of storage, on the rate of formation of Sotolon.

It is of general knowledge that to determine unambiguous kinetic model for a certain reaction it is very important to know the reaction stoichiometry and mechanism. However, as was explained above, the formation of Sotolon is very complex, involving not completely known mechanisms. Therefore, considering the global reaction mechanism, only an apparent reaction rate can be calculated and the resultant kinetics determined (36). As a result of experimental data modelisation, formation of Sotolon, both in the saturated and non-supplemented regimes of oxygen, followed a first order reaction kinetics. Also for both cases, the temperature dependence of the reaction rate constant was well described by the Arrhenius equation (see figures $8 \mathrm{~A}, 8 \mathrm{~B}$ ), respectively for the saturated and non-supplemented regime). 

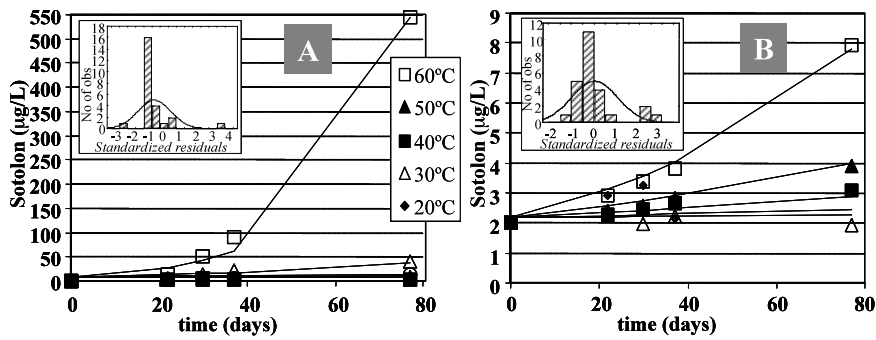

Figure 8: One step non-linear regression modelling for Sotolon formation for $A$-saturation regimes and B-not supplemented samples.

Statistical analysis using a one step non-linear regression method was applied in order to estimate kinetic parameters. Activation energies and rate constants estimated at the reference temperature of $40{ }^{\circ} \mathrm{C}$ and corresponding $95 \%$ confidence intervals are reported in Table 1.

Table 1. Kinetic parameters for the formation of Sotolon, using the one-step nonlinear regression method, for samples, with oxygen saturated and not supplemented regimes.

\begin{tabular}{lllcc}
$c=c_{0} \exp \left[t \times k_{r e f} \times \exp ^{-\frac{E a}{R} \times\left(\frac{1}{T}-\frac{1}{T_{r s}}\right)}\right]$ & model & Ea $(\mathbf{k J} / \mathbf{m o l})$ & $\mathbf{k}_{\text {ref }}\left(\mathbf{d a y s}{ }^{-1}\right)$ & $\mathbf{C}_{0}(\mu \mathrm{g} / \mathrm{L})$ \\
\hline$\left[\mathrm{O}_{2}\right]$ dissolved $=$ Saturation & first & $92.0 \pm 30.7$ & $0.0065 \pm 0.0049$ & $8.44 \pm 2.56$ \\
\hline$\left[\mathrm{O}_{2}\right]$ dissolved = Not Supplemented & first & $66.2 \pm 24.8$ & $0.0036 \pm 0.0022$ & $2.20 \pm 0.20$
\end{tabular}

For the saturated regime, the Sotolon concentration increases exponentially with temperature, illustrating the high sensitivity for this parameter. This fact is in agreement with the higher Arrhenius activation energy found for the saturated regime. The total consumed oxygen was for this set $30 \mathrm{mg} / \mathrm{L}$. On the other hand, without the presence of oxygen only a very slight increase of Sotolon formation for samples stored at $60^{\circ} \mathrm{C}$ was observed. This result is translated by the smaller reaction rate constant found for the non-supplemented regime.

Although predictions are out of the scope of this modelisation work, due to constraints of the experimental design, we have attempted to estimate Sotolon concentration of a 16 years Port wine, for a temperature of $17^{\circ} \mathrm{C}$, using both models for the two oxygen regimes. This was done, due to the fact that we had at our disposition real samples originated from the same wine lot, but stored on barrel (high $\mathrm{O}_{2}$ regime) and bottle (low $\mathrm{O}_{2}$ regime). The observed concentrations were respectively $90 \mu \mathrm{g} / \mathrm{L}$ and $23 \mu \mathrm{g} / \mathrm{L}$, surprisingly, in the same order of magnitude of the predicted values using both models for the two oxygen regimes, respectively, $83 \mu \mathrm{g} / \mathrm{L}$ (high $\mathrm{O}_{2}$ ) and $35 \mu \mathrm{g} / \mathrm{L}\left(\right.$ low $\mathrm{O}_{2}$ ). Nevertheless, in 
order to use these or other mathematical models as a predictive tool it seems clear that oxygen regimes needs to be taken into account.

\section{Conclusion}

Sotolon (3-hydroxy-4,5-dimethyl-2(5H)-furanone) concentrations correlates positively with time of aging of barrel storage Port. Within certain limits Sotolon can also correlate with the intensity of typical aroma related to the descriptors "nutty", "spicy" and the "perceived age" of barrel storage Port wine. This phenomenon can be demonstrated even with Sotolon additions to a unaged base port.

The quantification of this molecule both in "Colheita" and "Vintage" categories clearly showed a high dependence between Sotolon levels and maturation time and dissolved oxygen.

The Sotolon formation was studied as a function of temperature, $\mathrm{pH}, \mathrm{SO}_{2}$ and oxygen concentration. Temperature, followed by dissolved oxygen were the most important parameters influencing the rate of Sotolon formation. A first order model was applied and the Arrhenius equation described well the temperature dependence of the reaction rate constant. Therefore, oxygen regimes during aging have a major impact on "age perception" in this style of Port wines.

Considering the key role played by Sotolon on the sensorial "quality" of barrel aged Port wine, these findings seem promising in order to provide to the industry a mechanism of stock management, in particular for blended Port wines "Tawnys" category in order to modulate the "technological age" of Ports. 


\section{References}

1. Cantarelli C.; Etude de la madérisation et de sa prévention dans les vins blancs. Deuxième Symposium Inst. d'Oenologie. Bordeaux Cognac, 2, 1967, 392-407.

2. A C. Silva Ferreira, Bertrand A; Evolution de quelques constituants du vin de Porto au cours du vieillissement. Etude particulière de composés carbonylés. In Oenologie 95, 5eme Symposium International d'Oenologie; Lonvaud-Funel, A , Ed. Lavoisier Tec \& Doc: Paris, 1996 ; pp 419-423.

3. Simpson, R. Volatile aroma components of Australian Port wines. J. Sci. Food Agric. 1980, 31, 214-222.

4. Williams, A.A.; Lewis, M.L.; May, H.V. The volatile flavour components of commercial port wines. J. Sci. Food Agric., 1983, 34, 311-319.

5. V. A. P. Freitas, Paula Ramalho, Zélia Azevedo and Adelina Machado. Identification of some volatile descriptors of the Rock-Rose-Like Aroma of fortified red wines from Douro Demarcated region. J. Agric. Food Chem.; 1999, 47, 4327-4331.

6. Rogerson, F; H., Castro, N., Fortunato, Z., Azevedo, A, Macedo and V., Freitas. Chemicals with sweet Aroma Descriptors Found in Portuguese wines from the Douro Region: 2,6,6-Trimethylcyclohex-2-ene-1,4-dione and Diacetyl. J. Agric. Food Chem.; 2001, 49, 263-269.

7. Silva Ferreira, A.C.; Barbe, J.C.; Bertrand, A. Heterocyclic acetals from glycerol and acetaldehyde in port wines : evolution with aging. J. Agric. Food Chem., 2002, 50(9) 2560-2564.

8. Silva Ferreira, Rodrigues, P., Hogg, T.; Guedes de Pinho, P.;. Influence of Some Technological parameters on the formation of dimethyl sulfide, 2mercaptoethanol, methionol, and dimethyl sulfone in Port wines. J. Agric. Food Chem., 2003, 51(3) 727-732.

9. Silva Ferreira, A.C.; Barbe, J.C.; Bertrand, A. 3-Hydroxy-4,5-dimethyl2(5H)-furanone: A key Odorant of the Typicl Aroma of Oxidative Aged Port Wine. J. Agric. Food Chem., 2003, 51(3) 4356-4363.

10. Dubois P., Rigaud J. and Dekimpe J.;. Identification of 4,5dimethyltetrahydrofuran-2,3-dione in a Flor sherry wine. Lebensm. Wiss. Technol., 1976, 9, 366-68.

11. Martin B. and Etievant, P., X.; 1991. Quantitative determination of solerone and Sotolon in Flor Sherries by Two-Dimensional-Capillary GC. HRC \& CC. 14, 133-5.

12. Martin, B.; Etiévant, P. X.; Le Quéré, J. L.; Schlich, P. More clues about the sensory impact of Sotolon in flor sherry wines. J. Agric. Food Chem., 1992, 40, 475-78. 
13. Pham, T. T.; Guichard, E.; Pascal, S.; Charpentier, C. Optimal conditions for the formation of Sotolon from $\alpha$-ketobutyric acid in the French "Vin Jaune". J. Agric. Food Chem., 1995, 43, 2616-2619.

14. Shneider, R., Baumes, R.; Bayonove, C; Razungles, A . Volatiles compounds involved in the aroma of sweet fortified wines (vins doux naturels) from Grenache Noir. J. Agric. Food Chem. 1998, 46, 3230-3237.

15. Guichard E., Pham T. T. and Etievant P. X.; Quantitative determination of Sotolon in wines by high-performance liquid chromatography. Chromatographia, 1993. 37(9-10), 539-42.

16. Masuda M., Okawa E., Nishimura K. and Yunome H;. Identification of 4,5dimethyl-3-Hydroxy-2 $(5 H)$-furanone (Sotolon) and ethyl 9hydroxynonanoate in Botrytised wine and evaluation of the roles of compounds characteristic. Agric. Biol. Chem., 1984, 48, 2707-10.

17. Sulser H., Depizzol J. and Buchi W.; A probable flavoring principle in vegetable-protein hydrolysates. T. Food Sci., 1967 32, 611-15.

18. Lerk K. and Ambuhl M.,. Biotechnological production of 4,5-diméthyl-3hydroxy-2(5H)-furanone. in: Bioflavor 95. Analysis-Precursor StudiesBiotechnology; Etiévant, P.; Schreier, P., Eds.; Les Colloques no.75, INRA: Paris, 1995, p.p.: 381-84.

19. Blank I., Lin J., Fumeaux R., Welti D. H. and Fay L. B.;. Formation of 3Hydroxy-4,5-dimethyl-2 $(5 H)$-furanone (Sotolone) from 4-Hydroxy-Lisoleucine and 3-Amino-4,5-dimethyl-3,4-dihydro-2(5H)-furanone. $J$. Agric. Food Chem., 1996, 44, 1851-56.

20. Hofmann, T; Schieberle, P. Identification of potent aroma compounds in thermally treated mixtures of glucose/cysteine and rhamnose/cysteine using aroma extract dilution techniques. J. Agric. Food Chem., 1997, 45, 898906.

21. Hofman T. and Schieberle P.;. Identification of the key odorants in processed ribose-cysteine Maillard mixtures by instrumental analysis and sensory studies. Spec. Publ. - R. Soc. Chem., 1996, 197 (Flavour Science), $175-81$.

22. T. Konig, B. Gustche, M. Hartl, R. Hubsher, P. Schereier and W. Schwab. 3Hydroxy-4,5-dimethyl-2(5H)-Furanone (Sotolon) Causing an Off-Flavor of Its Formation Pathways during Storage of Citrus Soft Drinks. J. Agric. Food Chem., 1999, 47, 3288-3291.

23. Yaylayan, V. and Forage, N.G. 1991. Determination of the kinetics and mechanism of decomposition of triptophan amadori rearrangement product by RP-HPLC analysis. Journal of Agricultural and Food Chemistry, 39, 2, 364-369.

24. SAPORTA G.;. Probabilités analyse des donées et statistique, Ed., TechnipParis, 1990. 
25. Laboratory Methods for sensory Evaluation of Food, publication 1637, Communications Branch, Agriculture Canada, Ottawa K1a 0C7, ISBN: 0662-01271-2, 1982.

26. Sensory Evaluation Techniques. Morten Meilgaard, Gail Vance Civille, B. Thomas Carr. 3rd eds. 1999, CRC Press LLC.

27. Ribereau-Gayon, J.; Peynaud, E.; Ribereau-Gayon, P. and Sudraud, P. Traité d'Oenologie. Sciences et Techniques du Vin., Tome 1. Analyse et contrôle des vins. 1976, Dunod eds., Paris.

28. Bertrand, A. Formation des substances volatiles au cours de la fermentation alcoolique. Incidence sur la qualité des vins. Colloque Soc. Fr. Microbiol., Reims, 1981, 251-67.

29. Barbe, J.-C.; Silva Ferreira, A.C.; Bertrand A. Dosage de dérivés furaniques et pyraniques au cours de l'élevage et du vieillissement des vins de Sauternes. In Enologie $19996^{\text {ème }}$ Symposium International d'Enologie. Tec et Doc Ed., Paris, France, 2000, pp. 497-500.

30. Statistica Inc. (2001). Statistica Software: Release 6.0, Oklahoma, USA.

31. Van Boekel, M.A.J.S. 1996. Statistical aspect of kinetic modeling for food science problems. Journal of Food Science, 61, 3, 477-485, 489.

32. Arabshahi, A.; Lund, D.B. 1985. Considerations in calculating kinetic parameters from experimental data. J. Food Process Eng., 7, 239-251.

33. Couto, J. A. and Hogg, T.. Diversity of ethanol-tolerant lactobacilli isolated from Douro fortified wine: clustering and identification by numerical analysis of electrophoretic protein analysis. Journal of Applied Bacteriology, 1994, 76, 487-491.

34. Takahashi, K.; Tadenuma, M.; Sato, S. 3-Hydroxy-4,5-dimethyl-2(5H)furanone, a burnt flavouring compound from aged sake. Agric. Biol. Chem., 1976, 40, 325-330.

35. Martins, S. I. F. S. Unravelling the Maillard reaction network by multiresponse kinetic modelling. Ph.D. Thesis, wageningen University, The Netherlands, 2003.

36. Levenspiel, O., Kinetics of homogeneous reactions. In Chemical reaction engineering, $3^{\text {rd }}$ ed.; John Wiley \& Sons: New York, 1999; pp 13-32, chapter 2 . 